\title{
Management of esophageal foreign body using endoscopic approach: An experience from Kathmandu Medical College Teaching Hospital
}

\section{Shrestha D}

Diva Shrestha, Lecturer, Department of ENT and Head \& Neck Surgery, Kathmandu Medical College

\begin{abstract}
Background: Esophageal foreign body is a common otolaryngological emergency encountered in clinical practice. The cases with esophageal foreign body need prompt medical attention and appropriate endoscopic or surgical intervention. The type of foreign body varies in different age groups and the level of impaction also varies accordingly. The foreign body in upper esophagus can be removed with safer and easier non-surgical techniques.

Objectives: The objective of this study was to determine the demography, management approach and outcome of esophageal foreign body cases presented to Kathmandu Medical College Teaching Hospital.

Methodology: This is a prospective study conducted in Kathmandu Medical College Teaching Hospital. The data was collected from the medical records of cases that presented to Kathmandu Medical College Teaching Hospital with clinical diagnosis of esophageal foreign body from July 2013 to July 2017.

Results: Out of 101 cases of esophageal foreign body, there were $57 \%$ cases of chicken bone, followed by $17 \%$ mutton bone and $12 \%$ meat bolus. Among all, $71 \%$ cases had endoscopic removal of foreign body within six hours of presentation and $29 \%$ had endoscopic removal of foreign body between six to twelve hours. The most common age group was fifth decade of life. One patient had post-operative mediastinitis.

Conclusion: The endoscopic approach is the mainstay of management in foreign body esophagus and timely management leads to successful outcome.
\end{abstract}

Key words: Endoscopy, Esophagus, Foreign body

\section{INTRODUCTION}

$\mathrm{C}^{\mathrm{s}}$ sophageal foreign body is a common clinical condition encountered in clinical practice. It is a very common otolaryngological emergency. Esophageal foreign body is more common in children. The type of foreign body varies in different age groups. The type of management approach varies depending upon the age of the patient, type of foreign body, level of impaction and presence or absence of complications. The management approach can be endoscopic (rigid or flexible) or surgical. The foreign body in upper esophagus can be removed with safer and easier non surgical technique.

Impaction of foreign body in esophagus commonly occurs at sites of anatomical constrictions-at

Address for correspondence

Dr. Diva Shrestha

Lecturer, Department of ENT and Head \& Neck Surgery,

Kathmandu Medical College Teaching Hospital

E-mail: drdivaaiims@gmail.com cricopharynx, the levels of the aortic arch; the left main bronchus, and the diaphragm. The majority of foreign bodies that reach the gastrointestinal tract generally pass spontaneously. Similarly, 10-20\% will require non-operative intervention, and $1 \%$ or less will require surgery ${ }^{1}$. A study from India has shown that in elderly patients, especially with dementia, impacted dental prosthesis in esophagus can create serious problems ${ }^{2}$.

Endoscopic retrieval of both acute and chronic esophageal foreign body is preferred and is usually successful. The endoscopic removal of esophageal foreign body can be done with rigid endoscope or flexible fibreoptic endoscope. The use of different types of endoscope varies with the type of foreign body and site of impaction. The role of surgical intervention in the removal of esophageal foreign body appears when endoscopic removal is unsuccessful. This study aims to determine the demography, management approach and outcome of esophageal foreign body cases that presented to Kathmandu Medical College Teaching Hospital. 


\section{METHODS}

This prospective study reviewed the medical records of cases with clinical diagnosis of esophageal foreign body that were presented to Department of Ear Nose Throat Head and Neck (ENT-HNS), Kathmandu Medical College Teaching Hospital from July 2013 to July 2017. The inclusion criteria were the patients with clinical diagnosis of esophageal foreign body presenting to Kathmandu Medical College, age group upto 80 years and patient referred to ENT-HNS department for removal of esophageal foreign body. The patient with clinical diagnosis of esophageal foreign body with incomplete records and patients with clinical diagnosis of esophageal foreign body referred to other centre were excluded. The ethical approval for the study was obtained from Institutional Review Committee of Kathmandu Medical College. The data were analyzed using Microsoft Office Excel 2007 and SPSS version 25.

\section{RESULTS}

Out of total 101 cases of foreign body esophagus, one patient was excluded as patient had developed retropharyngeal abscess at the time of presentation. Of the remaining hundred, seventy one cases (71\%) had endoscopic removal of foreign body within six hours of presentation to emergency department and twenty nine percent had endoscopic removal of foreign body between six to twelve hours of foreign body ingestion.

The most common foreign body in esophagus was chicken bone (57\%) (Fig.1), followed by mutton bone and meat bolus which were seen in 17 and $12 \%$ respectively.

Sixty four percent of the patients were male and thirty six percent were female. The most common age group of patients with foreign body esophagus was fifth decade of life (Fig. 2). Seventy one percent of the patients presented with pain as the main complain where as twenty nine patients presented with difficulty in swallowing. Ninety nine percent of the patients were diagnosed by using X-ray (Fig.3) and one percent required Computed Tomography (CT) scan for diagnosis. One patient out of 101 who was referred to our center for foreign body removal from esophagus developed mediastinitis.

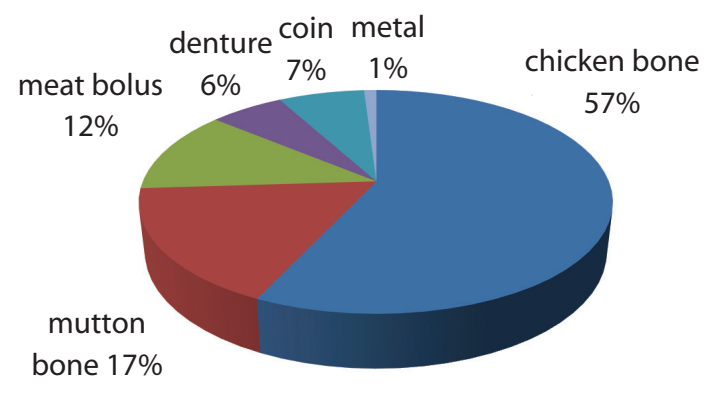

Figure 1: Types of foreign body esophagus

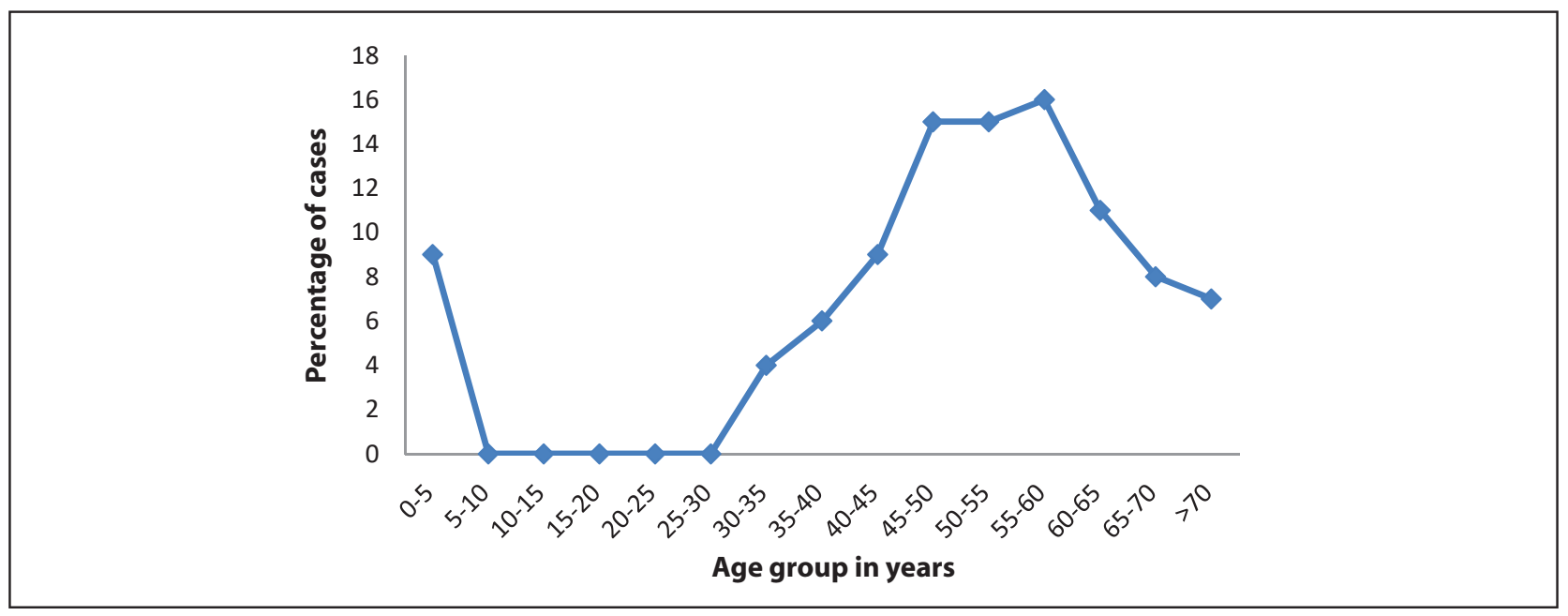

Figure 2: Age distribution of patients with foreign body esophagus 


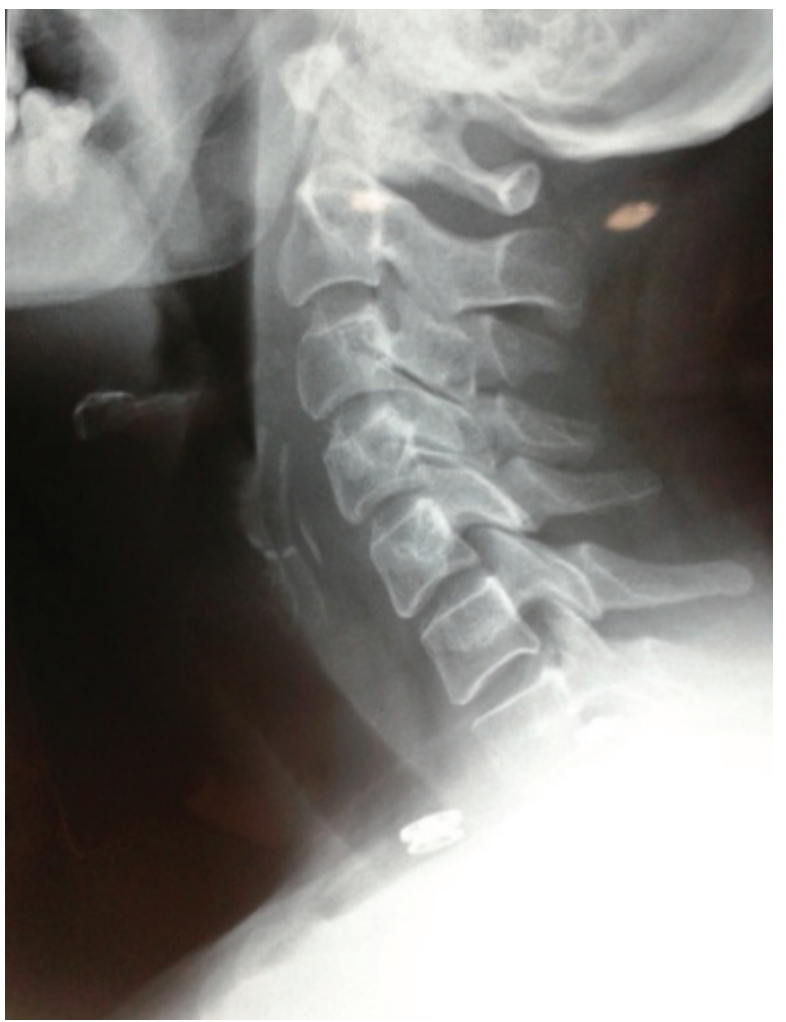

Figure 3: X ray neck showing foreign body in esophagus

\section{DISCUSSION}

Esophageal foreign body requires immediate and timely intervention. In our study, more than two third of the patients were managed within six hours of presentation. Shrestha $D$ et al in their study done in India reported cases where surgery was deemed necessary for the management of esophageal foreign body 3 . The inadequate management of esophageal foreign body can lead to serious complications. The delay in medical attention might lead to dreadful complications like tracheal compression, mucosal ulceration, inflammation, para or retropharyngeal abscess, mediastinitis, empyema, perforation, foreign body migration into adjacent structures like trachea or aorta, aortoesophageal fistula leading to catastrophic bleeding ${ }^{4}$. None of the cases in our study had complications during the hospital stay.

A study from Manipal Teaching Hospital by Koirala $\mathrm{K}$ et. al compared esophageal foreign body in pediatric and adult population the result of which showed that out of total cases of foreign body impaction, $44.4 \%$ patients were children and $55.5 \%$ were adults. Coin was the most common foreign body in the pediatric population $(82.1 \%)$ whereas bones were the commonest ones $(91.4 \%)$ in adults ${ }^{5}$. The study concluded that coins being the commonest foreign bodies in children were relatively easier to remove due to their higher location and less chances of trauma where as in the adults, bones being the commonest foreign body were difficult to remove due to the lower location and increased chances of trauma ${ }^{5}$. However, in our study the most common age group was in fifth and sixth decade and the most common foreign body was chicken bone.

In one year retrospective study, Baral BK et al from Dharan, Nepal concluded that the coin impacted at the cricopharynx and upper oesophagus can be safely, easily and quickly removed under direct vision with direct laryngoscopy and the Magill's forceps under propofol sedations ${ }^{6}$. The study had highlighted that alternative approaches to conventional endoscopic technique can be safe, short, and cost effective method of management in upper esophageal foreign body 6 . In our study, all the cases were successfully managed with rigid endoscopic technique.

A three year retrospective study from Rawalpindi Medical College in Pakistan by Aslam M et alin 175 cases concluded that the common foreign bodies were coins (55\%) and meat bolus (25\%) with $73 \%$ of the total patients being children between 2-7 years of age. They also concluded that cricopharyngeus was the commonest site of impaction?. A retrospective analysis of 163 cases of foreign body ingestion carried out in Tribhuban University Teaching Hospital in between April 2004 and October 2006 by Adhikari P et al showed that blunt foreign bodies were more common in children while sharp foreign bodies were in adults and the cricopharyngeal junction was the most common site of foreign body in children whereas was the oesophagus in adult ${ }^{8}$.

Ghimire A et al in their case report from BPKIHS in eastern Nepal have highlighted the need of prompt diagnosis and adequate surgical management in the management of esophageal foreign body. The case report further highlights the possibility of delay in diagnosis due to the unavailability of proper health facility in remote area in developing countries like Nepal which might lead to neglected cases of esophageal foreign body with lethal outcome like descending necrotizing mediastinitis. As most of the cases in our study was timely managed, there was less ( $2 \%$ ) complications encountered.

\section{CONCLUSION}

In conclusion, the endoscopic approach is the mainstay of management in foreign body esophagus and timely management leads to successful outcome. 


\section{REFERENCES}

1. Webb WA. Management of foreign bodies of the upper gastrointestinal tract: update. GastrointestEndosc. 1995;41:39-51. https://doi. org/10.1016/S0016-5107(95)70274-1.

2. Yadav R, Mahajan G, Mathur RM.Denture plate foreign body of esophagus. Ind J ThoracCardiovasc Surg. 2008;24:191-4. https://doi.org/10.1007/ s12055-008-0040-2.

3. Shreshtha D, Sikka K, Singh CA, Thakar A. Foreign Body Esophagus: When Endoscopic Removal Fails. Ind J Otolarngol Head Neck Surg. 2013;65(4):380382. https://doi.org/10.1007/s12070-013-0662-6.

4. Monnier $P$, Savary M. Foreign bodies of the esophagus: a retrospective study in 1436 adults. Proceedings of the International Congress of Thorax Surgery[Internet]. 1997 [Accessed on 15thfeb 2017]:197-200.

5. Koirala K, Rai S, Chhetri S, Shah R. Foreign Body in the Esophagus-Comparison Between Adult and
Pediatric Population. Nepal Journal of Medical Sciences. 2012;1:42-4. https://doi.org/10.3126/njms. v1i1.5797.

6. Baral BK, Joshi RR, Bhattarai BK, Sewal RB. Removal of coin from upper esophageal tract in children with Magill's forceps under propofol sedation. Nepal Med Coll J. 2010;12(1):38-41.

7. Aslam M, Shafi MS. Oesophageal foreign bodies at Rawalpingi General Hospital(An experience of 175 cases). Journal of Surgery Pakistan (International). 1997;2(4):14-6.

8. Adhiraki P, Shrestha BL, Baskota DK, Sinha BK. Accidental Foreign Body Ingestion: Analysis of 163 Cases. Int Arch. Otorhinolaryngol.2007;11(3):267-70.

9. Ghimire A, Bhattarai M, Kumar M, Wakode PT. Descending necrotizing mediastinitis: a fatal complication of neglected esophageal foreign body. Kathmandu Univ Med J.2007;5(1):98-101. 